\title{
A brief history of the periodic table
}

\author{
C. N. R. Rao* \\ Jawaharlal Nehru Centre for Advanced Scientific Research, Bengaluru 560 064, India
}

The United Nations declared 2019 as the International Year of the Periodic Table. On this occasion, it is most appropriate that we recount the story of this most useful and important contribution to science.

\section{Introduction}

IN the first century, hardly five elements were known. During this period, people still made objects out of bronze, brass and such materials. It was only in the 5th and 6 th centuries that iron became known and there were many important man-made objects fabricated during this period. Even in the 18th century, when chemistry as a subject was born (thanks to Lavoisier), only 20 elements were known. The need to classify elements became necessary only as scientists discovered more and more elements. There were many efforts to classify elements in various ways, but the most important contribution to this area was the periodic table, first proposed by Dmitri Mendeleev. The periodic table is an important happening in science. It is probably the greatest man-made table. In its present form, it has considerable information useful to scientists. Its use is immense and perennial. Scientists use it routinely to predict, design or explain various aspects of molecules and materials. In this brief article, we shall outline the brief history of the periodic table and describe how the evolution of this table occurred in the last 150 years.

\section{Evolution of the periodic table}

When the subject of chemistry got recognized in the late 18 th century, if the periodic table were constructed, it would have looked like Figure 1. Towards the beginning of the 19th century, many scientists thought of the concept of periodicity of periodic-properties of elements (Figure 2). The first one to examine this was Dobereiner in 1817 who talked about triads of elements based on similarities in properties. Typical triads are $(\mathrm{Cl}, \mathrm{Br}, \mathrm{I})$ and (Li, Na, K), but triads of many other elements could not be found. The idea of the spiral arrangement of elements to describe periodicity was presented by De Chancurtois in 1862. In 1864, Newlands described the law of Octaves. Then came the idea of the Periodic Law of Mendeleev in 1869. This marks a very important development in

*e-mail: cnrrao@jncasr.ac.in chemistry and materials science, the reason for us to celebrate its 150 th anniversary.

The status of science in 1869 was different. For example, the idea of atomic number was not known. Mendeleev therefore created a periodic table based on atomic masses. In Figure 3, the version of the periodic table described by Mendeleev in 1869 is shown. Here, the periods are rows and groups are columns.

Besides the tabular form, one of the other features of Mendeleev's table was that odd elements ( $\mathrm{Fe}, \mathrm{Co}, \mathrm{Ni}$, for example) were not placed in the main groups. He also predicted eka-boron and eka-aluminium. These elements were later discovered as scandium and gallium. The main conclusion from Mendeleev's work was that 'Properties of elements vary periodically with the atomic mass'.

It is important that we note that noble gases had not been discovered when Mendeleev worked on the periodic table. Helium was discovered in 1868 (Jenssen in Andhra Pradesh, India) and argon in 1894 (Rayleigh and Ramsay). Neon, Xenon and Krypton were discovered by Ramsay and Travers in 1898. More importantly, electron was discovered only in 1896, much after Mendeleev's work, and so was atomic structure by Rutherford (1911). In spite of these drawbacks, a modified version of Mendeleev's periodic table was used for nearly 50 years (Figure 4).

\section{Modern periodic table}

The modern version of the periodic table had to wait for the discovery of the atomic number by Moseley (1914). Arrangement of elements based on atomic number changed the entire picture. Understanding of the electronic structures of elements (and the Aufbau principle) gave the basis to come out with a table where transition elements found the right place. The discovery of transuranium elements by Seaborg and other man-made elements further changed the contents of the periodic table. The long form of the periodic table that we use today (Figure 5) came into being in 1985. In Figure 6, we show the chronology of the Modern periodic table.

The periodic table enables us to make useful comparisons and correlations between properties of elements. For example, in the alkali metal group, the atomic size increases and the ionization energy decreases as we go down the group. The electronegativity of elements in the first period increases as we go to the right, fluorine having the highest electronegativity. The number of 


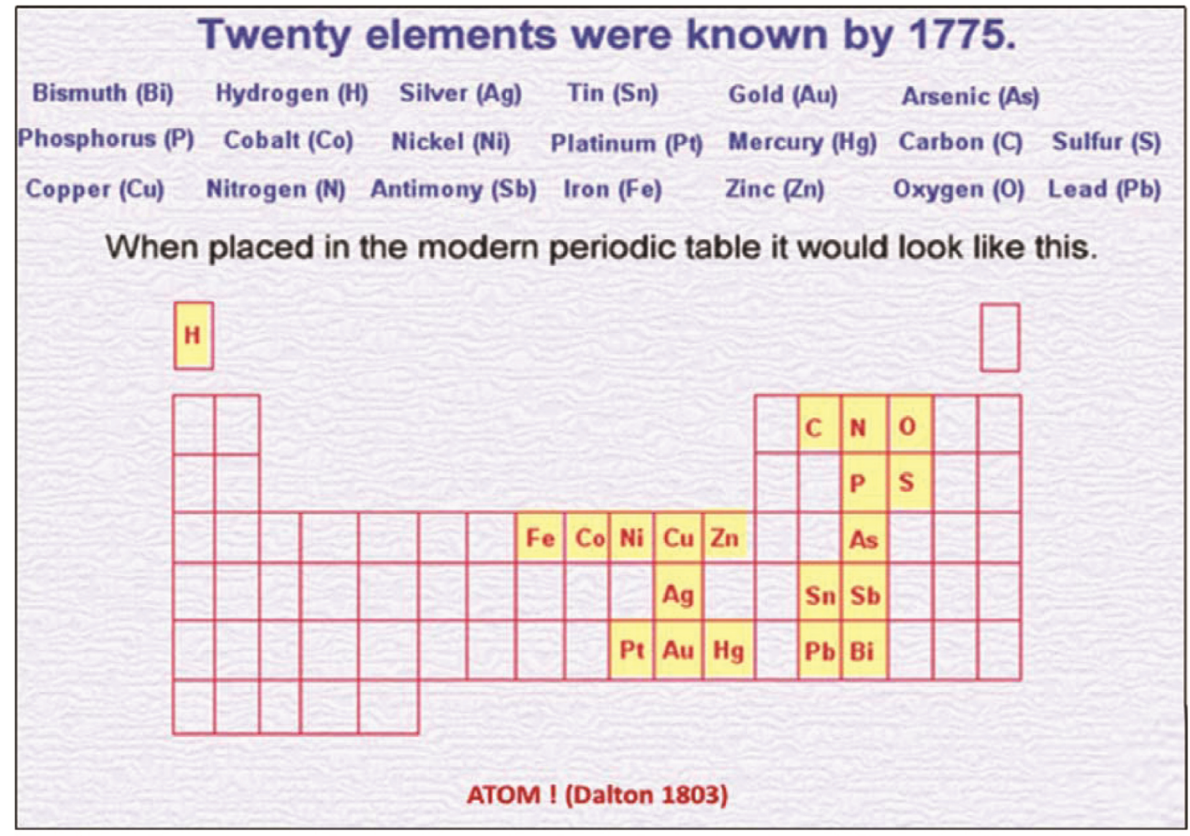

Figure 1. Hypothetical periodic table in 1773.

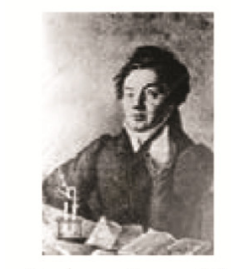

Dobereiner 1817

(Triads)

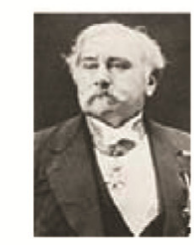

De Chancourtois 1862 (Spiral)

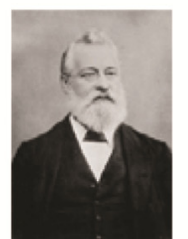

Newlands 1864 (Law of Octaves)

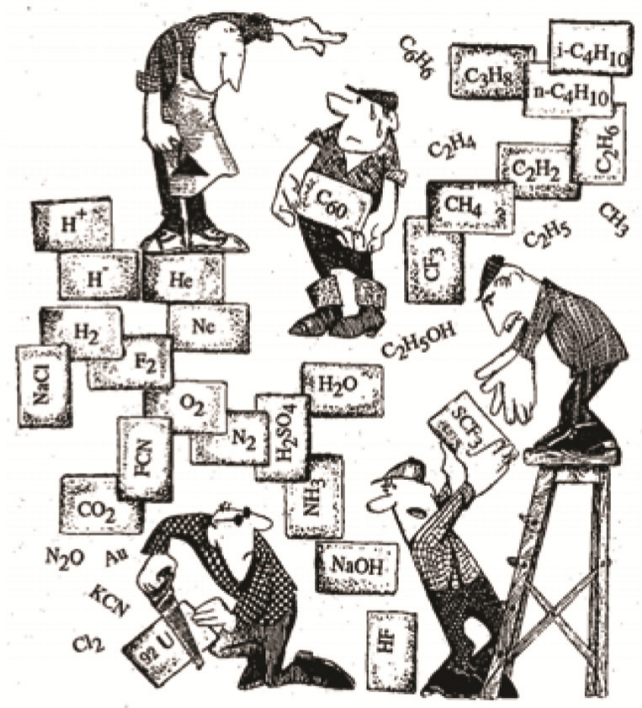

RUTHERFORD (1911)

Figure 2. Concept of periodicity (Sabero and Hefferlin, chem.msu.rc).

electrons in a halogen is one less than the corresponding noble gas. The number of electrons in an alkali metal is one electron more than the corresponding noble gas. In the rare earth series, the atomic size decreases as we go through the series from La to Lu (lanthanide contraction).
Many semiconductors as well as other materials have been made based on clues from the periodic table. For example, to imitate the valence of four of carbon (diamond), one can make compounds between a trivalent element with a pentavalent element (e.g. InP, GaN). An oxide CURRENT SCIENCE, VOL. 117, NO. 12, 25 DECEMBER 2019 
Period

\begin{tabular}{|c|c|c|c|c|c|c|l|}
\hline I & II & II & IV & V & VI & VII & VII \\
\hline & & & & & & & \\
\hline $\mathrm{Nr}$ & $\mathrm{Mg}$ & $\mathrm{B}$ & $\mathrm{C}$ & $\mathrm{N}$ & $\mathrm{O}$ & $\mathrm{V}$ & \\
\hline $\mathrm{K}$ & $\mathrm{Cr}$ & - & $\mathrm{TI}$ & $\mathrm{P}$ & $\mathrm{S}$ & $\mathrm{CI}$ & \\
\hline $\mathrm{Cu}$ & $\mathrm{Zn}$ & - & - & $\mathrm{As}$ & $\mathrm{Se}$ & $\mathrm{Br}$ & \\
\hline $\mathrm{Rb}$ & $\mathrm{Sr}$ & $\mathrm{V}$ & $\mathrm{Zr}$ & $\mathrm{Nb}$ & $\mathrm{Mo}$ & & \\
\hline
\end{tabular}

\section{\begin{tabular}{l|l}
$G$ \\
5 \\
0 \\
0
\end{tabular}}

Notice the gaps left in certain groups.

\section{Mendeleev}

a arranged the known elements in a tabular form.

- numbered the elemonts according to thoir atomic mass (mass number

a arranged them in an increasing order of the atomic mass.

a did not place odd elements in the main groups (Fe, Co, Ni).

Figure 3. Mendeleev's periodic table (1869)

\begin{tabular}{|c|c|c|c|c|c|c|c|c|}
\hline $\begin{array}{c}\text { Group } \\
0\end{array}$ & $a^{\prime} b$ & ${ }_{a}{ }^{11}$ & III & $a_{a} \quad b$ & $a^{v}$ & $a^{V T}$ & $\begin{array}{lll}a_{a} & \text { VII } & \\
\end{array}$ & VIII \\
\hline & H1 & & & & & & & \\
\hline He2 & Li3 & Be4 & Bs & C6 & N7 & O8 & F & \\
\hline Nelo & Na 11 & $\operatorname{Mg} 12$ & 113 & Si 14 & P 15 & $S 16$ & $\mathrm{Cl}_{17}$ & \\
\hline Ar18 & K 19 & $\mathrm{Ca} 20$ & Se 21 & 1722 & $\mathbf{v} 23$ & Cr 24 & Mn 25 & Fe 26, Co 27, Ni 28 \\
\hline & $\mathrm{Cu} 29$ & $\ln 30$ & Ga 31 & Ge 32 & As 33 & $\mathrm{Se} 34$ & Br 35 & \\
\hline Kr 36 & Rb 37 & Sr 38 & Y 39 & $\mathrm{Zr}+40$ & $\mathrm{Nb}+1$ & $\mathrm{Me} 42$ & Ic 43 & Ru H,Rh 45,Pd 46 \\
\hline & Ag 47 & $\mathrm{Cd}+8$ & In 49 & Sn 50 & Sb 51 & Te 52 & 153 & \\
\hline Xe 54 & $\begin{array}{c}\text { Cs } 55 \\
\text { Au } 79\end{array}$ & $\begin{array}{c}\text { Ba 56 } \\
\mathrm{Hg} 70\end{array}$ & $\begin{array}{r}57.71 \\
\text { Ti } 81 \\
\end{array}$ & $\begin{array}{r}\text { HI } 72 \\
\quad \mathrm{~Pb} 82 \\
\end{array}$ & \begin{tabular}{|c|} 
Ta 73 \\
Bi 83 \\
\end{tabular} & $\begin{array}{l}\text { W } 74 \\
\text { Po } 84\end{array}$ & \begin{tabular}{|r|} 
Re 75 \\
At 85 \\
\end{tabular} & Os 76, Ir 77, Pi 78 \\
\hline $\operatorname{Rn} 86$ & Fr 87 & Ra 88 & Ac 89 & Th 90 & Pa 91 & U 92 & $\mathrm{~N}_{p} 93$ & Pu $94, \mathrm{An} 95, \mathrm{Cm} 96$ \\
\hline
\end{tabular}

Figure 4. Later version of Mendeleev's periodic table.

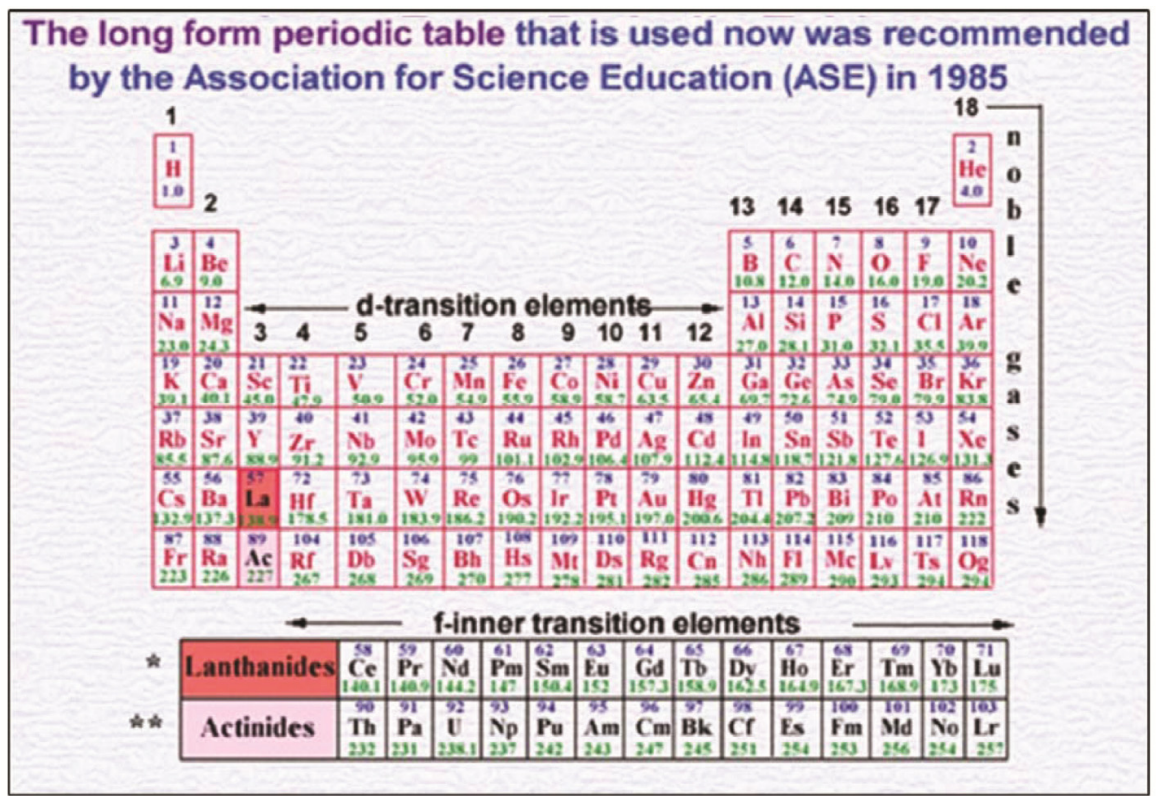

Figure 5. Long form of the 'Modern periodic table'. 


\begin{tabular}{|lll|}
\hline J. W. Dobereiner & Triads & 1817 \\
A. E. B. de Chancourtois & Spiral & 1862 \\
J. A. R. Newlands (U.K) & Law of octaves & 1864 \\
Meyers (Germany) & Atomic volume & \\
Mendeleev (Russia) & $\begin{array}{l}\text { Periodic law } \\
\text { (short form) }\end{array}$ & 1869 \\
Henry Moseley (U.K) & Atomic number & 1914 \\
$\begin{array}{l}\text { Long form of the periodic table } \\
\text { Present-day periodic table }\end{array}$ & & 1985 \\
\hline
\end{tabular}

Figure 6. Chronology of the modern periodic table.

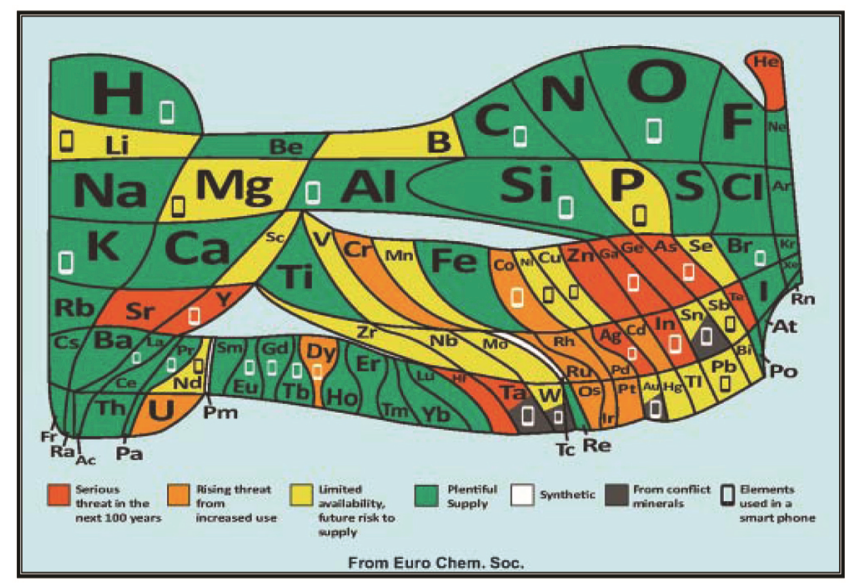

Figure 7. Periodic table based on the availability or abundance of elements (from Euro. Chem. Soc.) such as $\mathrm{TiO}_{2}$ can be transformed to TiNF wherein the size and number of electrons remain the same, but the properties are different.

Many years ago, when I started to work on perovskite oxides $\left(\mathrm{ABO}_{3}\right)$, I first thought of working on $\mathrm{LaCoO}_{3}$ because of its interesting properties. Soon, I realized that I should work on compounds with other transition metals $\left(\mathrm{LaMO}_{3}\right.$ with $\left.\mathrm{M}=\mathrm{Ti}, \mathrm{V}, \mathrm{Cr}, \mathrm{Mn}, \ldots, \mathrm{Ni}, \mathrm{Cu}\right)$ as well. Then, I decided to change the rare earth from $\mathrm{La}$ to $\mathrm{Pr}$, $\mathrm{Nd}, \ldots, \mathrm{Lu}$ and $\mathrm{Y}$, enabling me to generate a large galaxy of materials with different properties and showing different phenomena. One could work out a periodic table of these perovskite oxides.

\section{Some elements are becoming extinct}

All the elements are not available in plenty. Some are expensive and some are getting to be extinct. Rhodium is the most expensive metal, followed by ruthenium, gold and platinum in that order. A 'new' periodic table prepared by the European Chemical Society (Figure 7) is based on the availability of elements. Look at helium in red colour showing that it is getting very difficult to obtain and is not available in plenty. Lithium is also short in supply and it is therefore difficult to make lithium batteries indefinitely. Maybe, we should work on sodium batteries and hydrogen for energy.

Long live the periodic table! Let us salute Mendeleev.

doi: $10.18520 / \mathrm{cs} / \mathrm{v} 117 / \mathrm{i} 12 / 1963-1966$ 